\title{
A PERSONAL REFLECTION ON THE 50TH YEAR ANNIVERSARY OF THE OPTOMETRIC HISTORICAL SOCIETY
}

\author{
Lester Caplan, OD, MEd, FAAO \\ School of Optometry \\ University of Alabama at Birmingham \\ baltoeyedoc@mac.com \\ doi: 10.14434/hindsight.v50i1.26588
}

\section{Abstract}

Personal reflections of Dr. Lester Caplan, a founding member of the Optometric Historical Society, on his involvement with the OHS during the course of his career as a private practitioner in Baltimore, MD, as an academic at the University of Alabama, and his leadership in public health optometry at the local, state and federal level.

\section{Keywords}

American Optometric Association; Optometric Historical Society; Public Health; indian Health Service; University of Alabama

In March 2018, I received an email from the Editor of Hindsight: Journal of Optometry History, Dr. David Goss, informing me that the year 2019 will mark the 50th anniversary of the founding of the Optometric Historical Society (OHS) and that a special issue of the journal was planned to celebrate the event. He said that he was hoping to include some comments or an article from me, as an original member of the OHS. I thanked David for the invitation and went on to say that I would love to write an article for this special Hindsight edition. Among the topics that were suggested to me for an article were personal involvement with the OHS and any experiences that influenced me and benefitted my optometric work.
In 1969, the founding year of the Society, I was in private practice in Baltimore, MD. I recall joining the OHS when it first came on the scene, as I wanted to be a part of an organization that would not only provide our profession with the rich history of our past, but would continue to record, in one form or another (and how that form has changed over the intervening 50 years), the continuing growth of the profession well into the unforeseeable future. Little did I know or ever dream that I would possibly make a small contribution to that history. When David sent me the names of the original 34 founding members of the organization, only eight had a familiar ring: Hofstetter, Dablemont, E.B. Alexander, Irv Bennett, Kiekenapp, Knoll, Tannebaum and Paul. The only one I knew personally was Al Paul, O.D., a fellow Maryland optometrist. What really surprised me were the names not on the list, but which were very familiar to me, such as Henry Peters, O.D., A. Norman Haffner, O.D. and Irv Borish, O.D. I am sure they joined shortly thereafter as I recall their attendance and active participation in almost all of the early OHS meetings. Future noted optometric historians, such as David Goss, Arol Augsburger, Bob Newcomb, John Amos and many more had not yet graduated from optometry school or were in the very early stages of their optometric careers.

In 1968, as chair of the Maryland Optometric Association Committee on Public Health, I negotiated the inclusion of Optometric Services in the Title XIX (Medicaid) Program with Maryland's Department of Public Health. I believe that Maryland was the first state to approve optometric services for Medicaid recipients. In January, 1969, the year of the founding of the OHS, I was appointed the optometric consultant to the director of the Indian Health Service. It was this event that launched my career in the national public health arena and directly influenced and dictated almost every pivotal moment of my long optometric career.

In 1974, the Public Health and Environmental Health Section of the American Academy of Optometry invited me to present a paper at their annual meeting about the U.S. Public Health Service and, in particular, the Indian Health Service. The paper was published in the June 1975 edition of the American Academy of Optometry's journal. That, along with my 1978 article in the February 1978 AOA's journal, "The Long Road to Eye Care" (a history of the first 10 years of the Indian Health Service Optometry Program) deepened my appreciation of the OHS, the national optometric organization that would preserve the past and record the future.

My career path changed dramatically, over the years that followed. In 1979 I entered academia, joining the faculty of the University of Alabama at Birmingham School of Optometry. I frequently joked that my success in academia came about by my inability to hold a job, having started out as director of the Optometric Technician Program, then chief of Contact Lens Services, followed by assistant dean for Clinical Services (Director of Clinics) and director of the Externship Program. Each of these positions afforded me the opportunity to actively participate 
in national common interest groups and in some cases, if a group did not exist, help it organize, develop and grow. So over my 36 years in academia, writing about the history of several of these organizations became my passion. In addition to a number of Indian Health Service Optometry updates, I lectured and wrote articles about the Vision Care Section of the American Public Health Association, the Association of Optometric Contact Lens Educators, the Association of Schools and Colleges of Optometry's (ASCO) first Special Interest Group $(\mathrm{SIG})$; the Clinic Directors SIG and its predecessor the Association of Clinic Directors/Administrators of Schools and Colleges of Optometry (ACDASCO).

My only involvement with the OHS over the years was being a loyal lifetime member, a devoted attendee at almost all of its annual meetings and an avid reader of its outstanding Hindsight: Journal of Optometry History. All that changed in late 2013 when, Dr. John Amos, president of the OHS, asked me if I would be willing to be interviewed by him and Kirsten Pourroy Hébert, the Heritage Services Specialist for the Archives and Museum of Optometry. The Archives were starting an Oral History Project and Dr. Amos thought that my history as the Optometric Consultant to the Director of Indian Health Service for 16 years was a compelling story that should be heard and preserved in the archives. The interview was completed and Dr. Amos invited me to present that history at the Society's "Blast from the Past" lecture in conjunction with the 2015 AOA meeting. (Figure 1) In 2016, when I was honored with the Henry B. Peters Award by the Public Health and Environmental Health Section of the American Academy of Optometry, I lectured on my 66

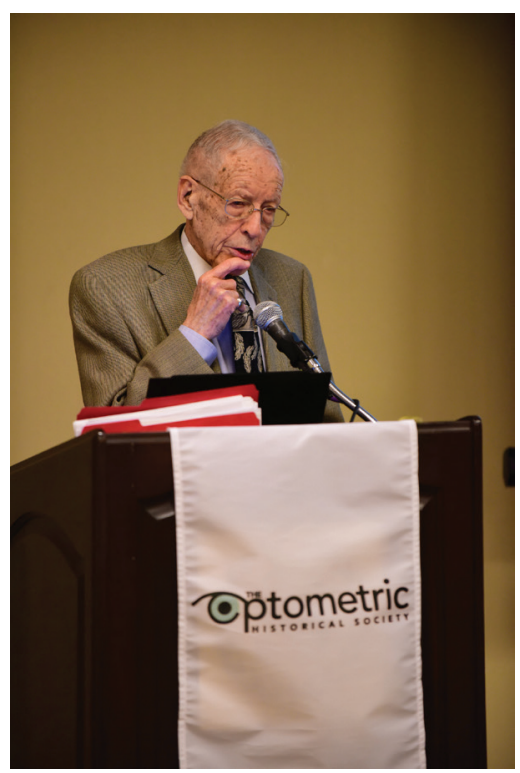

Figure 1: Dr. Lester Caplan speaking at Blast from the Past, June 2015, Seattle, WA. Image courtesy The Archives \& Museum of Optometry.

year history in optometry, relating significant periods in my professional life to the dramatic changes that were occurring in optometry during those same time periods. Shortly after that lecture I decided to expand on my PowerPoint presentation and write a detailed paper on the subject with the all-encompassing title, "Eye to I - 66 years of Optometry through the Eyes of a Clinician, Educator, Administrator, Consultant and Public Health Optometrist." Although I did not intend to submit it for publication, I did send it to Ms. Hébert for possible placement in the Archives and Museum of Optometry, as I felt that the paper had some historical value, presenting an overview of the profession from the last half of the twentieth century into a decade and a half of the twenty-first century. I was somewhat surprised, but naturally pleased, when I received an email from Dr. Goss, informing me that he had received the paper from Ms. Hébert and the reviewer of the article recommended it be published. The article was published in the January and July 2017 issues of Hindsight.
Being published in the Optometric Historical Society's journal was such an appropriate and nice way to bring an end to my optometric history writing career.

I am awed as I reflect on the 50 year history of the OHS the many brilliant and talented members who have added so much to the profession by their writings, teachings and most important of all, their lasting contributions that transitioned optometry from the vision care profession of the mid-twentieth century to the total eye and vision care profession of today. What would we have been without them: Borish, Haffner, Peters, Hopping, Gregg, Amos, Augsburger, Bennett, Runninger, Bailey, Morgan, Rosenbloom and so many other former and current members of the OHS whose impact on the history of our profession was equally notable. A very special "thank you" goes to Dr. Goss, who, as editor of Hindsight for half of the Society's 50 years, made sure that much of our profession's history would not be lost and that it would be saved for posterity. Happy 50th Anniversary to the OHS. 